\title{
Isolation and chromosomal assignment of human genes encoding cofactor of LIM homeodomain proteins, CLIM1 and CLIM2
}

\begin{abstract}
Cofactors of LIM homeodomain proteins (CLIM) are transcriptional activators that associate with the LIM homeoproteins and coordinate transcription. LIM homeoproteins and CLIMs are involved in a variety of developmental processes. Two CLIMs, CLIM1 and CLIM2, have been identified in the mouse. Here we report the isolation of human CLIM1 and CLIM2 cDNAs and the determination of their chromosome locations by using a human-rodent monochromosomal hybrid cell panel and a radiation hybrid mapping panel. The proteins deduced from human CLIM1 and CLIM2 cDNAs were composed of 373 and 375 amino acids, respectively, and had $97.3 \%$ and $98.7 \%$ amino acid identity, respectively, to their mouse counterparts. Human CLIM1 and CLIM2 proteins were $75.5 \%$ identical. Human CLIM1 and CLIM2 genes were mapped to the chromosome on 4p15.3 and 10q24-q25 regions, respectively. Mapping of a pair of developmentally important genes may provide new clues to the understanding of genetic disorders caused by these chromosome regions.
\end{abstract}

Key words CLIM $\cdot$ LDB $\cdot$ NLI $\cdot$ LIM domain $\cdot$ RH mapping · 4p15.3 $\cdot 10 \mathrm{q} 24-\mathrm{q} 25 \cdot$ SHFM3

N. Ueki $\cdot$ K. Yano $\cdot$ Y. Masuho $\cdot$ M. Muramatsu $(\bowtie)$

Helix Research Institute, 1532-3 Yana, Kisarazu, Chiba 292-0812,

Japan

Tel: +81-438-52-3951; Fax +81-438-52-3952

e-mail: mmasaaki@hri.co.jp

M. Muramatsu

Department of Biological Cybernetics, Medical Research Institute, Tokyo Medical Dental University, Tokyo, Japan

N. Seki

Laboratory of Gene Function II, Kazusa DNA Research Institute, Chiba, Japan

N. Seki · T. Saito

Genome Research Group, National Institute of Radiological

Sciences, Chiba, Japan

M. Ohira

Department of Biochemistry, Chiba Cancer Center, Chiba, Japan

\section{Introduction}

LIM homeoproteins consist of a large family of transcription factors that play essential roles in embryonic development, organogenesis, and pattern formation (Dawid et al. 1998). LIM homeoproteins consist of two LIM domains and a DNA-binding homeodomain. Recently, a family of nuclear proteins that bind to the LIM domains of LIM homeoproteins was isolated from the mouse (Jurata et al. 1996; Bach et al. 1997). This protein family currently consists of two members, CLIM1 and CLIM2 (cofactor of LIM homeodomain protein). CLIM2 is also known as LIMdomain binding (LDB1) (Agulnick et al. 1996) and nuclear LIM interactor (NLI) (Jurata et al. 1996). CLIM1 and CLIM2 can synergize the transcriptional activity of LIM homeoproteins (Bach et al. 1997). They can also form complexes with other transcription factors, indicating that CLIMs may be involved in a wide spectrum of gene regulation (Bach et al. 1997; Visvader et al. 1997; Wadman et al. 1997). However, the precise role of CLIM1 and CLIM2 in vivo still needs to be determined.

Transcription factors in embryonic development are occasionally involved in tumorigenesis and congenital abnormalities. For example, LIM homeoproteins hLH-2 and LMX1B are known to be involved in chronic myelogenic leukemia (Wu et al. 1996) and nail-patella syndrome (Vollrath et al. 1998), respectively. To this end, we isolated and determined chromosomal location of human CLIM1 and CLIM2 genes. This information should prove valuable in designing studies to evaluate their cellular function and relation to diseases.

\section{Materials and methods}

Cloning of human CLIM1 and CLIM2 cDNAs

An initial CLIM1 cDNA fragment was isolated during the course of screening for nuclear proteins. (Ueki et al., in 
press). To obtain the $5^{\prime}$ region of the CLIM1 gene, primers 5'-TGT TTG TTA GCC CCA TCC TGG TG-3' (according to the sequence of CLIM1) and 5'-CAC ACA GGA AAC AGC TAT GAC CAC TAG-3' (according to the sequence of the library vector) were designed, and PCR was performed using a human fetal brain cDNA library (GibcoBRL, Gaithersburg, MD, USA). To obtain human CLIM2 cDNA, we searched with BLAST against the dbEST database for sequences with significant homology to mouse CLIM2 cDNA (GenBank Accession No. U70375) and found two ESTs (AA569020 and AA194121). PCR primers, 5'-TGT TCC TCA AAG TCA TTC AAG CTG TAC TCG-3' and 5' $^{\prime}$-AGA TGC TCA GTC TCT TCA TTC TGT CTT CTG $\mathrm{C}-3^{\prime}$, were designed according to these sequences. A human CLIM2 cDNA was cloned by the RTPCR method using these primers and the human fetal brain cDNA library as a template. The parameter for PCR was 30 cycles of $94^{\circ} \mathrm{C}$ for $30 \mathrm{~s}, 61^{\circ} \mathrm{C}$ for $30 \mathrm{~s}$, and $72^{\circ} \mathrm{C}$ for $2 \mathrm{~min}$. PCR products were cloned into pT7Blue $(\mathrm{R})$ vector (Novagen, Madison, WI, USA), and nucleotide sequences were determined by using an ABI377 sequencer.

\section{Mapping of human CLIM1 and CLIM2 genes}

Chromosomal assignment of CLIM1 and CLIM2 genes was determined by using PCR analysis of NIGMS humanrodent somatic cell hybrid mapping panel 2 (Coriell Cell Repositories, Palo Alto, CA, USA). CLIM1 gene-specific primers were 5'-GTG TGC GTG CGT CTA CTT TGT-3' and 5'-TGA AAG GAG AAG AAT AGA AGG-3'; CLIM2 gene-specific primers were $5^{\prime}$-GCA TTT GCC TCC ATC TTC ACC-3' and 5'-AGC TTT ACC CCT CTA TTA CCA-3'. Human, mouse, and hamster genomic DNA were included as controls. PCR was carried out in a final volume of $10 \mu \mathrm{l}$ containing $1 \times$ LA-PCR buffer (Takara, Kyoto, Japan). The parameter for PCR was 30 cycles at $95^{\circ} \mathrm{C}$ for $20 \mathrm{~s}$ and $62^{\circ} \mathrm{C}$ for $1 \mathrm{~min}$. Radiation hybrid mapping used a Genebridge 4 mapping panel (Research Genetics, Huntsville, AL, USA) and the same primers as just described. The data vector was submitted to Whitehead Institute/MIT Center for STS mapping server, and statistical analysis was performed using the RHMAPPER software package (http://www-genome.wi.mit.edu/cgi-bin/contig/ rhmapper.pl).

\section{Results}

Isolation of human CLIM1 and CLIM2 cDNAs encoding the entire ORFs

Combining the sequences of the initial CLIM1 cDNA fragment and that of the $5^{\prime}$ portion obtained by rescreening, the resultant human CLIM1 cDNA was 2330bp (GenBank Accession No. AF047337) and encoded a protein of 373 amino acids (a.a.) (Fig. 1). The human CLIM1 protein showed $97.3 \%$ amino acid identity to the mouse CLIM1 protein. The mouse CLIM1 cDNA has two alternative splicing forms of CLIM1a and CLIM1b (Bach et al. 1997), which encode different ORFs in the carboxyl-terminal domain. The CLIM1 cDNA we cloned was the counterpart of the mouse CLIM1a spliced form.

The human CLIM2 cDNA cloned by RT-PCR was $1240 \mathrm{bp}$ (AB016485) and encoded a protein of 375 a.a. (Fig. 1). The human CLIM 2 protein showed $98.7 \%$ amino acid identity to the mouse CLIM2 protein. Alignment of human CLIM1 and CLIM2 proteins showed that both were $75.5 \%$ identical throughout the entire molecule (Fig. 1). Two potential nuclear localizing signals were present in both proteins (underlined in Fig. 1), and no other known domains could be found.

\section{Mapping of human CLIM1 and CLIM2 genes}

Using CLIM1-specific primers, a PCR product of $145 \mathrm{bp}$ was detected in human genomic DNA, control DNA, and somatic cell hybrids containing only human chromosome 4 . The RH mapping data vector for CLIM1 was 0100000101 $\begin{array}{llll}0010000100 & 2011010010 & 0010000100 & 0011111000\end{array}$ 1102001010111001100000000000010000000002010 . The consequent report indicated that the CLIM1 gene was mapped (LOD > 3.0) between markers D4S1601 and D4S934 (Fig. 2a, left panel). The position of the gene was $0.90 \mathrm{cR}$ proximal to the marker D4S1601. D4S1601 maps $84.57 \mathrm{cR}$ from the top of chromosome 4 linkage group. Loci D4S1601 and D4S934 have been approximately mapped to the 4p15.3 region (Riess et al. 1996).

Using CLIM2-specific primers, a PCR product with the expected size of $164 \mathrm{bp}$ was detected in human genomic

hCLIM1:M-SSTPHDPFYSSPF-GPFYRRHTPYMVPEYRIVIEMNKRLOSRTEDSDNLWWDAFATEFFEDDATLTLSFCLEDGPKRYTIGRTLIPRYFSTVFEGGV hCL IM2 MLDRDVGPTEMYPPTYLEEG I GRHTPYGNOTDYRIFFLLNKRLONWTEECDNLWWDAFTITEFFEDDAMLTI TECLEDGPKRYTI GRTLIPRYFRSIFEGGA

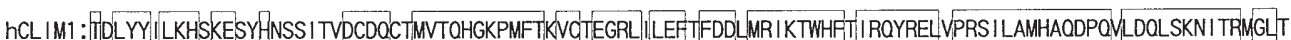
hCLIM2:UTELYYVLKHPKEAFHSNFVSLDCDQGSMVTOHGKPMFTOVOVEGRLYLEFMEDDMMR I KTWHFSIROHREL IPRSILAMHAODPOMLDOLSKNITRCGLS

hCLIM1 :NFTLNYLRLCVILEPMOELMSRHKTYNLSPRDCLKTCLFOKWORMVAPPAEPTROPTTKRRKRKNSTSSTSNSSAGNNANSTGSKKKTTAAANLSLSSOVP hCL IM2:NSTLNYLRLCVILEPMOELMSRHKTYSLSPRDCLKTCLFOKWOBMVAPPAEPTRQOPSKRRKRKMSGGSTM-SSSGGGNTNNSNSKKKSPASTTFALSSOVP

hCLIM1: DVMVGEPTLMGGEFGDEDERLITRLENTOYDAANGMDDEEDFNNSPALGNNSPWNSKPPATOETKSENPPPPASO hCLIM2:DVMWGGEPTLMGGEFGDEDERLITRLENTOFDAANGIDDEDSFNNSPALGANSPWNSKPPSSQESKSENPTSQASO

Fig. 1 Amino acid sequence alignment of human CLIM1 and CLIM2 proteins. A hyphen indicates that this residue is not present. Identical residues are boxed. The putative nuclear localization signals are underlined. GenBank accession numbers for human CLIM1 and CLIM2 cDNAs are AF047337, and AB016485, respectively 


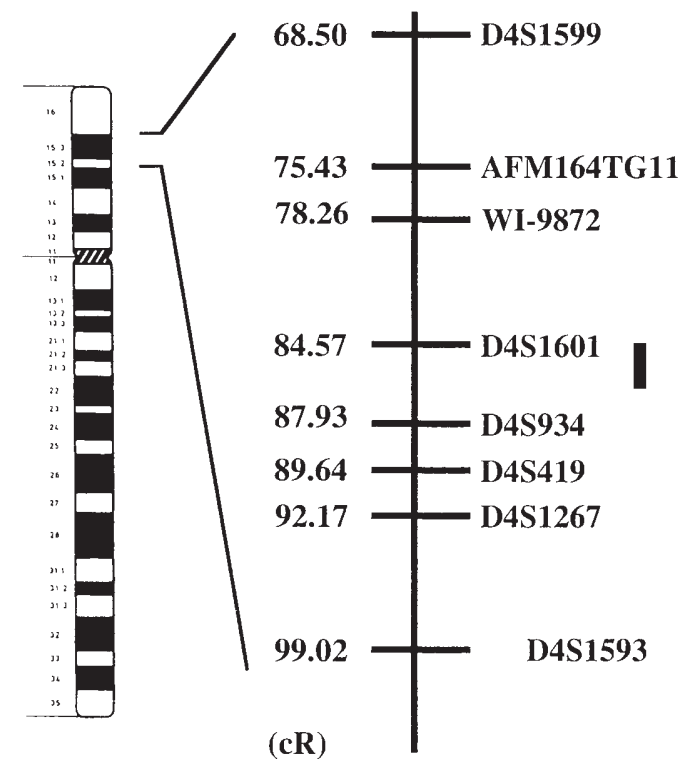

Chromosome 4

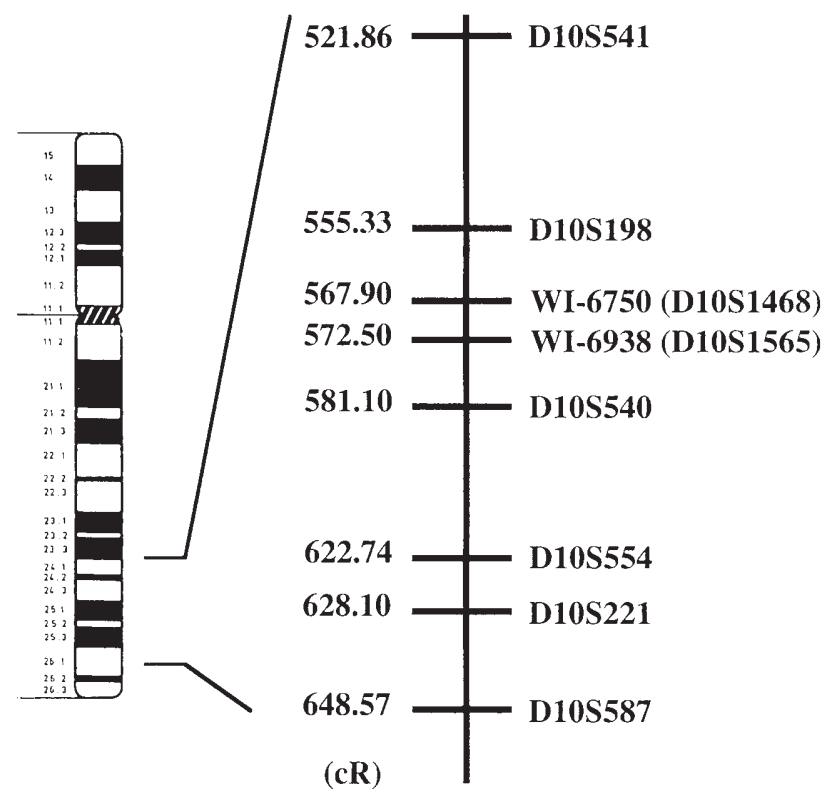

Chromosome 10
Fig. 2 a, b Schematic representation of human CLIM1 and CLIM2 loci. a Chromosomal placement of human CLIM1 and CLIM2 genes at relative distances to framework markers on the WICGR radiation hybrid map of the human genome. The approximate corresponding cytogenic locations of CLIM1 and CLIM2 are indicated by vertical bars. Distances are in centirays $(c R)$ from the top of chromosome 4 and chromosome 10 linkage groups. b Location of CLIM2 gene and other genes in the 10q24-q25 region. CLIM2, Pax2, PITX3, Hox11, MXI1, LIMAB1, FGFR2, and the SHFM3 region are indicated by vertical bars. The locations were determined by OMIM Gene Map and references in the text. The distances between the markers are in centirays $(c R)$.

DNA, control DNA, and somatic cell hybrids containing only human chromosome 10 . The $\mathrm{RH}$ mapping data vector for the CLIM2 gene was 1000110010000010000100010100110 00001010100000110000001001001000001000000110100011 1010001001001 . The consequent report indicated that the CLIM2 gene was mapped (LOD > 3.0) between markers WI-6750 and WI-6938 (Fig. 2a, right panel). The position of the gene was $1.92 \mathrm{cR}$ distal to the marker WI-6750. The marker WI-6750 maps $567.90 \mathrm{cR}$ from the top of chromosome 10 linkage group. Loci WI-6750 and WI-6938 have been approximately mapped to the $10 \mathrm{q} 24-\mathrm{q} 25$ region (Meitinger et al. 1997).

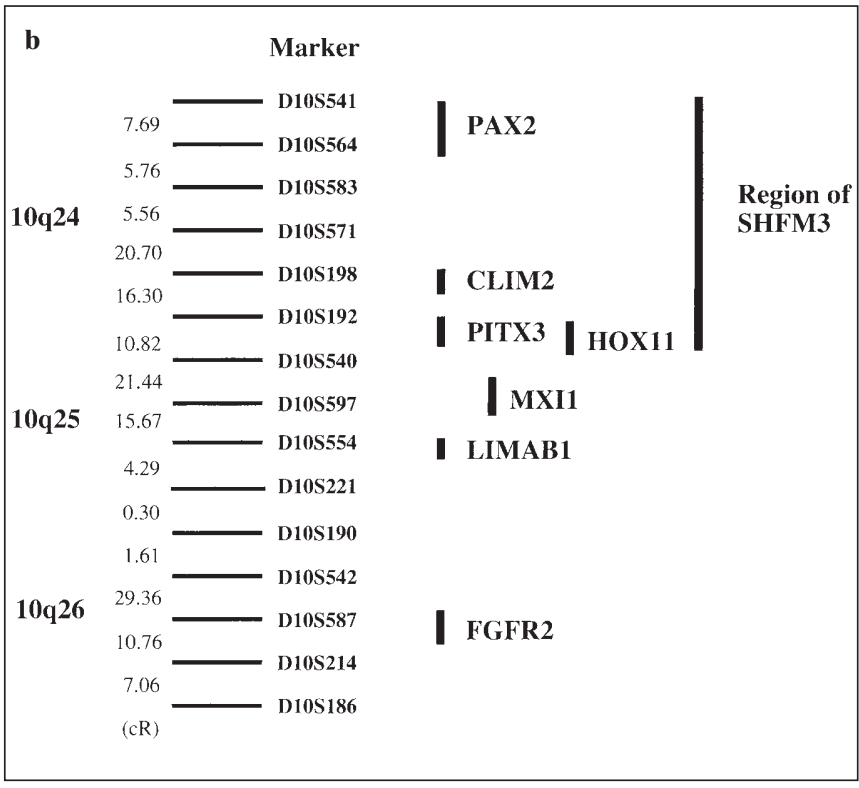

\section{Discussion}

In the present study, we isolated human CLIM1 and CLIM2 cDNAs and mapped their chromosomal locations. CLIMs are highly conserved among species, and homologs are found in Xenopus laevis (GenBank Accession No. U74360), in Danio rerio (AF031375), and also in Drosophila (AF010328). The Drosphila CLIM, Chip, is present at numerous sites along the salivary gland polytene chromosomes, suggesting a novel function of the gene product in chromosome regulation (Morcillo et al. 1997). Whether or 
not mammalian CLIMs have similar function needs to be determined.

Human CLIM1 and CLIM2 were mapped to the 4p15.3 and 10q24-q25 regions, respectively. No information is available for the chromosome location of the mouse CLIM1 gene at present. The mouse CLIM2 gene (alias LDB1) was recently mapped to the distal region of mouse chromosome 19, which is syntenic with human chromosome $10 \mathrm{q}$ (Yamashita et al. 1998). Our mapping result indicates that human CLIM2 resides in the syntenic region.

The 10q24-q25 region is rich in genes involved in development, such as Pax2, Hox11, PITX3, HMX2, MXI1, $L I M A B 1$, and FGFR2 (Kim et al. 1997; Meitinger et al. 1997; Semina et al. 1998). The location of CLIM2 relative to these genes is shown in Fig. 2b. With regard to diseases, 10q24-q26 is a region of frequent loss of heterozygosity in human tumors, including glioblastoma (Rasheed et al. 1995), prostate cancers (Komiya et al. 1996), endometrial carcinomas (Nagase et al. 1996), and thyroid tumors (Zedenius et al. 1996). Thus, CLIM2 can be included as a positional candidate for one of the several tumor suppresser genes in this region.

Other chromosomal gains or losses of 10q24-q25 without identification of a specific gene has also been reported in cases of congenital abnormalities. One such disease is the autosomal dominant split hand/split foot malformation (SHFM) 3. The SHFM3 region as determined by Nunes et al. (1995) and Gurrieri et al. (1996) includes CLIM2 (see Fig. 2b). Given the role of homeotic genes in pattern formation, its cofactor CLIM2 might be considered as a positional candidate of the SHFM3 gene in this region.

Our precise chromosomal positioning of the CLIMI and CLIM2 genes may contribute toward ongoing positional candidate approaches for the aforementioned disease genes linked to these chromosomal loci.

\section{References}

Agulnick AD, Taira M, Breen JJ, Tanaka T, Dawid IB, Westphal H (1996) Interaction of the LIM-domain binding factor Lbd1 with LIM homeodomain proteins. Nature (Lond) 384: 270-272

Bach I, Carriere C, Ostedroff HP, Anderson B, Rosenfeld MG (1997) A family of LIM domain associated cofactors confer transcriptional synergism between LIM and Otx homeodomain proteins. Genes Dev 11: 1370-1380

Dawid IB, Breen JJ, Toyama R (1998) LIM domains: multiple roles as adapters and functional modifiers in protein interactions. Trends Genet 14: 156-162

Gurrieri F, Prinos P, Tackels D, Kilpatrick MW, Allanson J, Genuardi M, Vuckov A, Nanni L, Sangiorgi E, Garofalo G, Nunes ME, Neri G, Schwartz C, Tsipouras P (1996) A split hand-split foot (SHFM3) gene is located at $10 \mathrm{q} 24 \rightarrow 25$. Am J Med Genet 62: 427-436

Jurata LW, Kenny DA, Gill GN (1996) Nuclear LIM interactor, a rhombotin and LIM homeodomain interacting protein, is expressed early in neuronal development. Proc Natl Acad Sci USA 93: 11693-11698

Kim AC, Peters, LL, Knoll JH, Van-Huffel C, Ciciotte SL, Kleyn PW, Chishti AH (1997) Limatin (LIMAB1), an actin-binding LIM protein, maps to mouse chromosome 19 and human chromosome $10 \mathrm{q} 25$, a region frequently deleted in human cancers. Genomics 46 : 291-293

Komiya A, Suzuki H, Ueda T, Yatani R, Emi M, Ito H, Shimazaki J (1996) Allelic losses at loci on chromosome 10 are associated with metastasis and progression of human prostate cancer. Genes Chromosomes Cancer 17: 245-253

Meitinger T, Scharfe C, Call K, Moschonas N (1997) Report of the second international workshop on human chromosome 10 mapping 1997. Cytogenet Cell Genet 78: 184-194

Morcillo P, Rosen C, Baylies MK, Dorsett D (1997) Chip, a widely expressed chromosomal protein required for segmentation and activity of a remote wing margin enhancer in Drosophila. Genes Dev 11: $2729-2740$

Nagase S, Sato S, Tezuka F, Wada Y, Yajima A, Horii A (1996) Deletion mapping on chromosome 10q25-q26 in human endometrial cancer. Br J Cancer 74: 1979-1983

Nunes ME, Schutt G, Kapur RP, Luthardt F, Kukolich M, Byers P, Evans JP (1995) A second autosomal split hand/split foot locus maps to chromosome 10q24-q25. Hum Mol Genet 4: 2165-2170

Rasheed BK, McLendon RE, Friedman HS, Friedman AH, Fuchs HE, Bigner DD, Bigner SH (1995) Chromosome 10 deletion mapping in human gliomas: a common deletion region in 10q25. Oncogene 10: 2243-2246

Riess PO, Kozak C, Omman GJ (1996) Report of the fourth international workshop on human chromosome 4 mapping 1996. Cytogenet Cell Genet 74: 57-69

Semina EV, Ferrell RE, Mintz-Hittner HA, Bitoun P, Alward WL, Reiter RS, Funkhauser C, Daack-Hirsch S, Murray JC (1998) A novel homeobox gene PITX3 is mutated in families with autosomaldominant cataracts and ASMD. Nat Genet 19: 167-170

Ueki N, Oda T, Kondo M, Yano K, Noguchi T, Muramatsu M (in press) Genetic selection for genes encoding nuclear targeted proteins. Nat Biotechnol

Visvader JE, Mao X, Fujiwara Y, Hahm K, Orkin SH (1997) The LIMdomain binding protein $\mathrm{Ldb} 1$ and its partner LMO2 act as negative regulators of erythroid differentiation. Proc Natl Acad Sci USA 94: $13707-13712$

Vollrath D, Jaramillo-Babb VL, Clough MV, McIntosh I, Scott KM, Lichter PR, Richards JE (1998) Loss-of-function mutations in the LIM-homeodomain gene, LMX1B, in nail-patella syndrome. Hum Mol Genet 7: 1091-1098

Wadman IA, Osada H, Grutz GG, Agulnick AD, Westphal H, Forster A, Rabbitts TH (1997) The LIM-only protein Lmo2 is a bridging molecule assembling an erythroid, DNA-binding complex which includes the TAL1, E47, GATA-1 and Ldb1/NLI proteins. EMBO J 16: $3145-3157$

Wu HK, Heng HH, Siderovski DP, Dong WF, Okuno Y, Shi XM, Tsui LC, Minden MD (1996) Identification of a human LIM-Hox gene, $\mathrm{hLH}-2$, aberrantly expressed in chronic myelogenous leukaemia and located on 9q33-34.1. Oncogene 12: 1205-1212

Yamashita T, Agulnick AD, Copeland NG, Gilbert DJ, Jenkins NA, Westphal H (1998) Genomic structure and chromosomal localization of the mouse LIM domain-binding protein 1 gene, Ldb1. Genomics 48: 87-92

Zedenius J, Wallin G, Svensson A, Bovee J, Hoog A, Backdahl M, Larsson C (1996) Deletions of the long arm of chromosome 10 in progression of follicular thyroid tumors. Hum Genet 97: 299-303 